\title{
RNA Polyadenylation Inhibition
}

National Cancer Institute

\section{Source}

National Cancer Institute. RNA Polyadenylation Inhibition. NCI Thesaurus. Code C21054.

RNA Polyadenylation Inhibition involves events or activities that directly hinder the covalent addition of polyadenylyl sequences to the 3 prime end of a nascent mRNA transcript. 